\title{
The role of fatty acids in the mechanical properties of beeswax*
}

\author{
Robert BuCHWALD ${ }^{1}$, Michael D. BREED ${ }^{2}$, Louis BJosTAD ${ }^{3}$, Bruce E. HIBBARD ${ }^{4}$, \\ Alan R. GREENBERG ${ }^{5}$ \\ ${ }^{1}$ Department of Integrative Biology, 3060 VLSB, University of California, Berkeley, \\ CA, 94708, USA \\ ${ }^{2}$ Department of Ecology and Evolutionary Biology, EBIO, CB 334, University of Colorado, Boulder, \\ CO, 80309-0334, USA \\ ${ }^{3}$ Department of Bioagricultural Sciences and Pest Management, Colorado State University, Fort Collins, \\ CO, 80523, USA \\ ${ }^{4}$ USDA-ARS, Curtis Hall, University Of Missouri Columbia, MO, 65211-7020, USA \\ ${ }^{5}$ Department of Mechanical Engineering, UCB 427 University of Colorado, Boulder, \\ CO, 80309-0427, USA
}

Received 3 July 2008 - Revised 1 December 2008 - Accepted 18 March 2009

\begin{abstract}
Beeswax is a mixture of many organic compounds, including hydrocarbons, wax esters, and fatty acids. Because fatty acids in beeswax also serve as social signals, we explored the functional significance of the fatty acids. The removal of the fatty acids from beeswax results in diminished yield stress, resilience, stiffness, and proportional limit stress of beeswax samples. Addition of stearic acid to beeswax enhances all of these properties except resilience. Artificial wax mixtures show a positive correlation between the amount of stearic acid in the wax mixture and yield stress. Unsaturated fatty acids found in beeswax behave similarly, with respect to their effects on the mechanical properties of artificial wax mixtures. Fatty acid concentration showed significant variation among colonies, particularly among the unsaturated fatty acids. We interpret these findings with respect to the mechanical properties of beeswax and the role of fatty acids in communication among bees.
\end{abstract}

Apis mellifera / wax / fatty acid / yield stress / stiffness

\section{INTRODUCTION}

For most observers, the outstanding feature of honeybee's nest is the hexagonal structure of the comb (Weaire and Phelan, 1994). Much has been made, and justifiably so, of the economy of this famous structure, particularly of how the hexagonal formation maximizes strength and minimizes investment in construction materials (Pirk et al., 2004; Kaatz, 2006). However, architecture does not exist independently of construction materials, and

Corresponding author: M.D. Breed,

michael.breed@colorado.edu

* Manuscript editor: Peter Rosenkranz less attention has been paid to the properties of beeswax as a construction material, and to the role the properties of beeswax plays in the manufacture of the comb (Hepburn and Kurstjens, 1988, but see Pirk et al., 2004 for a discussion of the thermoplastic properties of beeswax). Our goal is to elucidate the role of one of the major classes of components of beeswax, fatty acids, in shaping the properties of wax as a construction material. We chose to focus on fatty acids because of their known function in communication within colonies (Breed, 1998) and their characteristics as polar compounds, which differentiates them from the otherwise largely nonpolar suite of compounds in beeswax. 
The wax of the western honeybee, Apis mellifera L., is a complex, viscoelastic material comprised of at least 80 compounds (Aichholz and Lorbeer, 1999): primarily hydrocarbons, wax esters and fatty acids (Tulloch, 1980). Some of these chemicals are important for honeybee nestmate recognition, but their mechanical role in beeswax is unexplored. We investigated the mechanical properties of nestmate recognition chemicals in beeswax using a variety of quantitative mechanical tests. Our results further our understanding of the evolution of social recognition and how cues may be co-opted from sources already present in the environment that may be exposed to unrelated selective pressures (Reeve, 1989; Ratnieks, 1991).

Beeswax is produced endogenously by specialized organs in adult bees (Blomquist et al., 1980; Cassier and Lensky, 1995; Hepburn et al., 1991), then manipulated in the mandibles where salivary secretions are added (Kurstjens et al., 1985) and finally is placed in in the growing comb structure. Beeswax does experience some aging effects (Fröhlich et al., 2000a), but its composition is relatively stable over time. The thermal properties of beeswax contribute to heat retention and thermoregulation in the hive (Hepburn et al., 1983). Beeswax also has interesting structural properties that vary among species (Kurstjens et al., 1985; Morgan et al., 2002; Buchwald et al., 2006).

Beeswax is also important as a source of nestmate recognition cues (Breed et al., 1995; Breed and Stiller, 1992; D'Ettorre et al., 2006). With the exception of stearic acid, each of the prominent fatty acids in beeswax serves as a cue in honeybee nestmate recognition (Breed, 1998). The recognition cues include two saturated fatty acids (palmitic and tetracosanoic) and four unsaturated acids (palmitoleic, oleic, linoleic, and linolenic) (Breed, 1998; Breed et al., 1998, 2004a; Fröhlich et al., 2000b, 2001; Brockman et al., 2003). The non-active compound, stearic acid, is the most abundant component in the free fatty acid fraction of beeswax, but the active compounds are also present in substantial quantities (Breed, 1998). In addition to the fatty acids, oddchained alkenes, such as z-9-tricosene, are also recognition cues (Breed et al., 2004b). These alkenes are present in much smaller quantities than the corresponding n-alkanes, which seem not to function as cues (but see Chaline et al. 2005).

While the chemical composition of beeswax is relatively well known, the contribution of individual compounds, or classes of compound, to the functions of the wax are less well understood. We examined the contribution of the fatty acids used in honeybee nestmate recognition to the mechanical properties of beeswax, independent of the wax architecture or, geometry. We compared three treatments of beeswax: natural wax with fatty acids removed, natural wax supplemented with additional fatty acids, and untreated wax. We then produced artificial wax mixtures composed of the primary beeswax components and varied either the relative proportion or the identity of the fatty acid component. We tested the role of fatty acids in the mechanical properties of beeswax using two methods. First, we manipulated the relative proportion of fatty acids in natural beeswax and tested the wax mechanical properties. Then we created model waxes and varied both the relative proportion of fatty acids as well as the identity of the fatty acid, then tested the wax mechanical properties. Finally, we analyzed the fatty acid composition of natural beeswax.

\section{METHODS}

\subsection{Collection}

We collected virgin beeswax by removing newly constructed comb from Apis mellifera research hives at the University of Colorado apiaries. The comb was free-hanging; foundation was not provided for the combs used in these experiments.

\subsection{Removal and addition of fatty acids from natural wax}

Free fatty acids were removed from beeswax following the technique described by Warth (1956), which uses ethanol in reflux. This protocol prevents the formation of pores when removing free fatty acids from the specimens. To produce a wax with an 
artificially increased fatty acid component, stearic acid (a naturally-occurring component of beeswax) was purchased from Sigma-Aldrich ( $99 \%$, capillary GC) and added to melted wax, thereby increasing the fatty acid content of the natural mixture from $14.0 \%$ to $42.0 \% \mathrm{w} / \mathrm{w}$.

\subsection{Simplified wax mixtures}

Our model waxes contained representative compounds from the three primary hydrocarbon groups found in beeswax: pentacosane, representing the nhydrocarbon fraction, palmityl palmitate, representing the wax ester fraction, and one of several fatty acids. All substances are naturally occurring components of A. mellifera wax (Aichholz and Lorbeer, 1999, 2000). In these mixtures the hydrocarbon to wax ester ratio was held constant to equal the ratio of these compound classes in beeswax (18\% and $68 \%$, respectively). First, we varied the relative percentage of the free fatty acid component using only palmitic acid. For the final experiments, we kept the free fatty acid concentration equal to the total free fatty acid component in A. mellifera wax (14\%) but varied the identity of the free fatty acid used for that component. We tested two saturated acids (palmitic and lignoceric) and three unsaturated acids (palmitoleic, linoleic and oleic) all of which are used by A. mellifera for nestmate recognition (Breed et al., 1998). All chemicals were purchased from SigmaAldrich and were of the highest purity available (>98\%).

\subsection{Mechanical characterisation}

To determine the mechanical properties of the wax treatments independent of wax architecture, we utilized wax test samples of identical geometry (Buchwald et al., 2006). The wax was melted and then poured into a mould and allowed to cool to room temperature $\left(25^{\circ} \mathrm{C}\right)$. Once solidified, we removed the wax from the mould and sectioned it into identical right, circular cylinders $(17.8 \mathrm{~mm} \times$ $8.1 \mathrm{~mm})$. These samples were then placed in an Instron 5800 universal electromechanical test system and compressed under controlled conditions using a crosshead velocity of $10 \mathrm{~mm} / \mathrm{min}$. Because previous work has shown no difference among results obtained in compression or in tension when testing the mechanical behavior of beeswax at relatively low levels of strain (Morgan et al., 2002), we conducted our experiments in compression to eliminate the difficulties associated with gripping small, soft samples. The applied load and displacement of the upper platen were measured throughout the test and then converted into engineering stress-strain values using the initial cross-sectional area and length of the cylinders.

From the specimen stress-strain curves, the following standard engineering mechanical parameters were obtained: stress at the proportional limit, stress at the yield point, stiffness and resilience. The proportional limit identifies the end of the initial linear stress-strain region, the yield point represents a common measure of the transition from elastic to permanent deformation, the stiffness is the ratio of stress to strain in the elastic region, and the resilience refers to the amount of energy required for complete elastic deformation. Artificial mixtures were melted, moulded and tested following the same methods.

\subsection{Intercolonial variation in fatty acids}

To extract free fatty acids from the surfaces of honey bees, we removed any pollen from the bees and placed each bee in a separate vial that had been cleaned twice with dichloromethane. We then added $1.0 \mathrm{~mL} 1 \mathrm{M} \mathrm{NaOH}$ and $1.0 \mathrm{~mL}$ dichloromethane and shook for $2.0 \mathrm{~min}$, timed with a stopwatch. This brief period of shaking is believed to limit extraction to the surface of the bee, rather than the interior. The $1 \mathrm{M} \mathrm{NaOH}$ solution contained salts of free fatty acids from the surface of the bee.

For analysis of the free fatty acids we added $2.0 \mathrm{~mL} 1 \mathrm{M} \mathrm{HCl}$ to the $1 \mathrm{~mL}$ sample of $1 \mathrm{M} \mathrm{NaOH}$ containing the acids. A check with $\mathrm{pH}$ paper verified acidification of the solution. After addition of $1.0 \mathrm{~mL}$ dichloromethane the sample was shaken to form an emulsion which was centrifuged for $5 \mathrm{~min}$ to separate the solvent layers. A check with $\mathrm{pH}$ paper verified a $\mathrm{pH}$ of 6 , assuring that all the free fatty acids were protonated by the excess of $\mathrm{HCl}$. We then filtered the dichloromethane containing the free fatty acids into a new vial, and dried the solution completely with $\mathrm{N}_{2}$. Following drying, the acids were resuspended in $10 \mathrm{~mL}$ of hexane containing 5 micrograms eicosane as an internal standard. Addition of $0.5 \mathrm{~mL}$ boron trifluoridemethanol (14\% solution, Sigma Chemical Co., Saint Louis, Missouri), heated at $60{ }^{\circ} \mathrm{C}$ for $30 \mathrm{~min}$, formed methyl esters from the fatty acids. After addition of $1.0 \mathrm{~mL}$ hexane and $1.0 \mathrm{~mL} \mathrm{H}_{2} \mathrm{O}$ the mixture was 

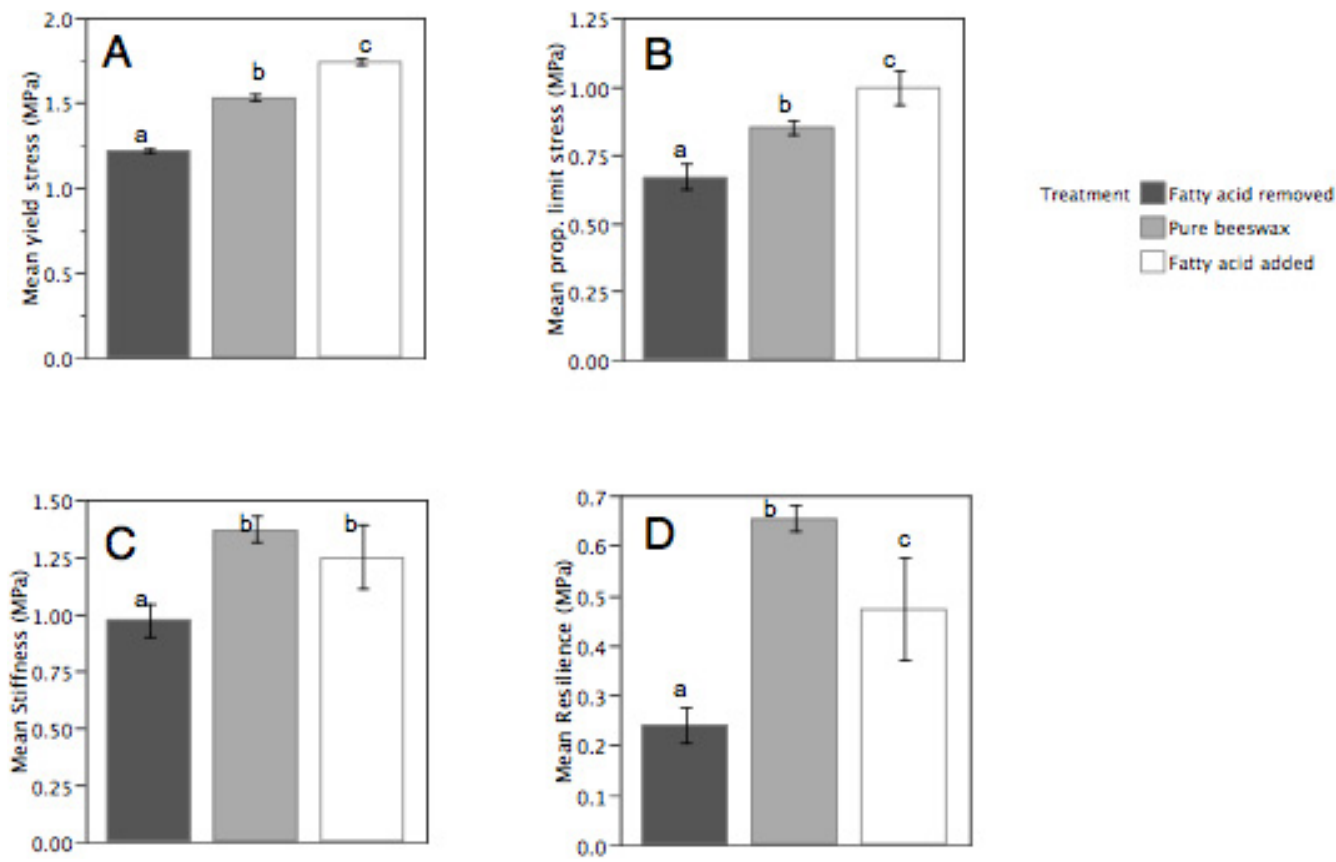

Figure 1. The effect of fatty acids on the mechanical properties of beeswax. Values represent means and standard errors for beeswax with the free fatty acids removed, unmodified beeswax, and beeswax with added stearic acid. Four mechanical properties were examined: yield stress (A), stress at the proportional limit (B), stiffness (C) and resilience (D). $N=6$ samples for each column. Matching letters above columns indicate no significant difference between the columns; differing letters indicate a significant difference.

shaken and the $\mathrm{H}_{2} \mathrm{O}$ discarded. One or two subsequent washes neutralized the $\mathrm{pH}$. After filtering the hexane containing the methyl esters, we evaporated the solvent with $\mathrm{N}_{2}$ until $10.0 \mathrm{~mL}$ remained. Analysis of $2.0 \mathrm{~mL}$ of the solution by gas-liquid chromatography on a Supelcowax capillary GLC column $(30$ meters $\times 0.25 \mathrm{~mm}$ ID) followed $(1.0 \mathrm{~min}$ at $60{ }^{\circ} \mathrm{C}$, ramped up at $10{ }^{\circ} \mathrm{C}$ per min to a final temperature of $250^{\circ} \mathrm{C}$, which was held for $10 \mathrm{~min}$ ). Compounds were identified by comparison of mass spectra and retention times with those of authentic standards.

\section{RESULTS}

\subsection{Removal and addition of fatty acids from natural wax}

We found that the fatty acids used for nestmate recognition in honeybees also contribute in a significant way to the mechanical properties and hence the structural characteristics of beeswax. Removal of the fatty acids from beeswax, or addition of a fatty acid, affects all of the mechanical properties measured. Removal of fatty acids from beeswax decreased, and the addition of fatty acids increased, the yield stress (ANOVA: F2,20 $=101.2, P<$ $0.0001)$ and stress at the proportional limit (ANOVA: F2,20 = 10.7, $P<0.001$ ) (Figs. $1 \mathrm{~A}$ and $\mathrm{B}$, respectively). Beeswax with fatty acids removed was less stiff than natural beeswax, but addition of fatty acids had no effect on this parameter (ANOVA: F2,20 $=4.27, P=0.028$ ) (Fig. 1C). Pure beeswax was the most resilient, followed by beeswax with added fatty acids, then by beeswax with fatty acids removed (ANOVA, F2,20 = 11.1, $P<0.001$ ) (Fig. 1D). In summary, the results in Figure 1 support the hypothesis that free fatty acids strengthen beeswax. 


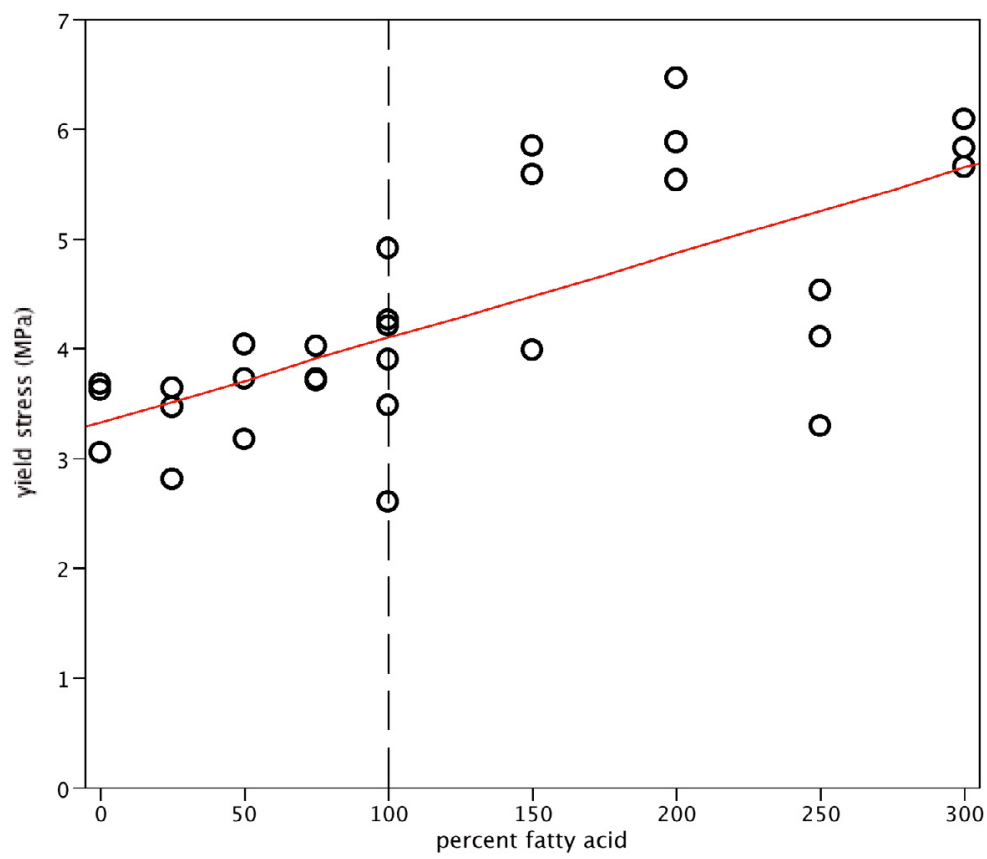

Figure 2. Compressive yield strength of artificial wax mixtures containing pentacosane, palmityl palmitate and palmitic acid at the specified percentage. The composition of $100 \%$, marked by a dashed line on the abscissa, indicates a free fatty acid component equal to that found in A. mellifera wax; a composition of $50 \%$ represents half the normal concentration, $200 \%$ double, and so on. The linear relationship between percentage free fatty acid (FFA) and yield strength is described by the equation $y=0.0078 x+3.324 . \mathrm{N}=3$ samples for each concentration, except $100 \%$, for which $\mathrm{N}=6$.

\subsection{Simplified wax mixtures}

To further explore the mechanical role of fatty acids in beeswax, we prepared model waxes for two experimental treatments. First, we varied the percentage of fatty acid in the samples. We found that higher concentrations of palmitic acid resulted in higher yield strengths (d.f. $=1,28, \mathrm{R}=0.68, \mathrm{R} 2=0.47, \mathrm{t}=$ 4.96, $\mathrm{CL}=0.005,0.011, P<0.0001$ ) (Fig. 2). The same relationship was found when examining the effect of increasing palmitic acid percent on the mechanical parameters of stress at the proportional limit (d.f. $=1,28 \mathrm{R}=0.59$, $\mathrm{R}^{2}=0.34, \mathrm{t}=3.83, \mathrm{CL}=0.002,0.007$, $P<0.001)$ and resilience d.f. $=1,28 \mathrm{R}=$ $0.56, \mathrm{R}^{2}=0.32, \mathrm{t}=3.61, \mathrm{CL}=0.001,0.003$, $P<0.01)$. Our model wax sample with the same relative concentrations as natural wax (represented by a dashed line in Fig. 2) has higher compressive yield strength than natu- ral beeswax. This is probably due to the lack of alkenes and unsaturated fatty acids in the model.

Next, we kept the hydrocarbon and wax ester and fatty acid fractions in the same relative proportions, but incorporated different fatty acids. We found significant variation in the mechanical properties in compression including yield stress (ANOVA: F4,50 = 182.09, $P<0.0001$ ) (Fig. 3A), stiffness (ANOVA: $\mathrm{F} 4,50=29.05, P<0.0001$ ) (Fig. 3B), resilience (ANOVA: $\mathrm{F} 4,50=137.53, P<$ 0.0001) (Fig. 3C), stress at the proportional limit (ANOVA: $\mathrm{F} 4,50=2.98, P<0.05$ ) (Fig. 3D), depending on which fatty acid was present (Fig. 3). Post-hoc statistical testing revealed that the unsaturated acids did not differ significantly for any of the mechanical properties measured. However, the two saturated acids differed significantly from the unsaturated acids for all measures. Thus, substitution 

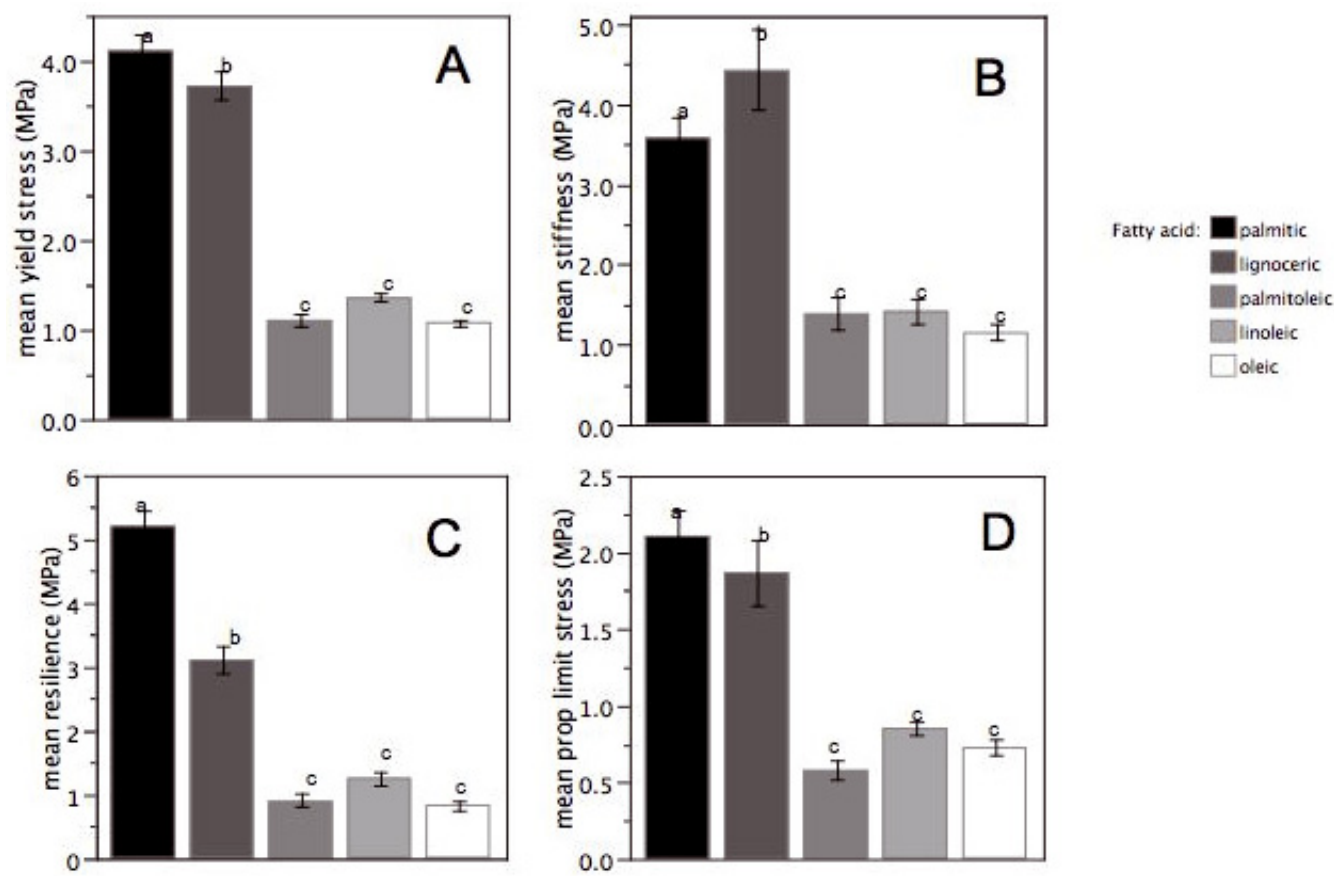

Figure 3. Mechanical properties (mean \pm standard errors) of model waxes (18\% pentacosane, $68 \%$ palmityl palmitate, $14 \%$ fatty acid) with varying fatty acid compositions. Four mechanical parameters were measured: compressive yield stress (A), stiffness (B), resilience (C) and compressive stress at proportional limit (D). $\mathrm{N}=10$ samples for each column. Matching letters above columns indicate no significant difference between the columns; differing letters indicate a significant difference.

of one fatty acid for another, within the unsaturated group, does not affect the mechanical properties of the wax, but substitution of a saturated for an unsaturated acid, or vice versa, does result in statistically significant changes.

\subsection{Intercolonial variation in fatty acids}

Six fatty acids, palmitic, palmitoleic, oleic, linoleic, linolenic and tetracosanoic acids were prominent in our GC analyses. Four of these acids varied significantly in relative concentration among colonies (Fig. 4).

\section{DISCUSSION}

Our results support the hypothesis that fatty acids are important in conferring the appropriate mechanical properties to beeswax. Al- though we do not know which wax mechanical properties are most important to honeybees in nest construction, it seems reasonable that beeswax must have the necessary combination of compliance (inverse of stiffness) and resilience to be formed into comb, yet must have the strength to enable the honeycomb structure to bear substantial weight. Natural selection has likely acted on at least one, if not several, of these properties. Our finding that unaltered beeswax was more resilient than wax with fatty acids removed or added suggests that selection may have acted to optimize the fatty acid content of beeswax for its resilience.

Our results also suggest that phenotypic variation in the relative proportion of fatty acids, within the group of saturated or the group of unsaturated fatty acids, in A. mellifera wax would have little or no impact on the mechanical properties of the beeswax. This 

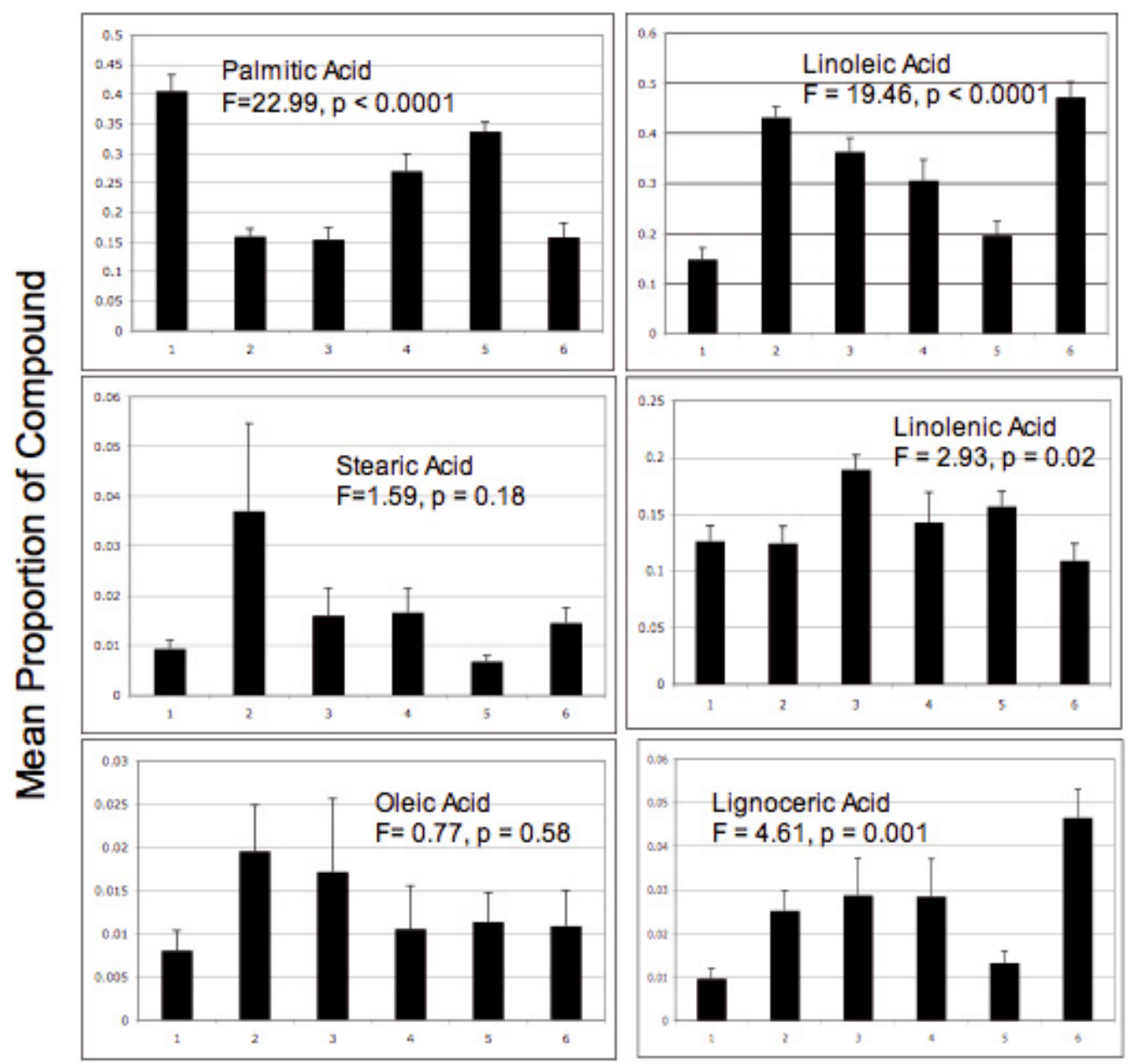

\section{Colony Number}

Figure 4. Intercolonial variation in relative proportion of fatty acids in washes of workers. Each bar represents the mean proportion of that acid (with standard error) of the total extracted from the bee. The numbers on the $\mathrm{X}$ axis represent colonies; corresponding bars for the different acids are from the same colony. $\mathrm{N}=11$ workers from colonies 1 and 2, 10 from colonies 3, 4 and 6, and 8 for colony 5. ANOVA results are given for each acid; the degrees of freedom for the ANOVAs are 5,54.

allows flexibility in phenotypic expression and variation in cue phenotype among colonies. Variation in the contribution of unsaturated acids to the recognition phenotype appears to be largely neutral with regard to mechanical behaviour, at least within the bounds of maintaining the relative proportions of saturated and unsaturated acids within the overall mixture of compounds in beeswax. The nestmate recognition cues on the surface of bees are acquired by exposure to the comb wax (Breed et al., 1998), and fatty acids are important among the cues used by honeybees for nestmate recognition (Breed et al., 2004a). Although the role of these chemicals in recognition behaviour is well studied, their role in the mechanical properties of beeswax has not previously been examined. 
Based on our results, it is reasonable to predict that the composition of beeswax should be relatively invariant for the compounds that are not used in social recognition, such as stearic acid, and more highly variable for the compounds that can be neutrally substituted, such as palmitoleic, linoleic and oleic acids. Indeed, this appears to be the case. Our gas chromatographic results show that stearic acid and oleic acids do not vary significantly in concentration among wax samples from different colonies, while palmitoleic acid, linoleic acid, linolenic acid, and lignoceric acid do vary significantly. It is particularly noteworthy that stearic acid neither varies significantly among colonies nor is active as a nestmate recognition cue.

In contrast to honeybees, which use endogenously produced nest materials as nestmate recognition cues and some insects that use visual cues for recognition (Tibbetts, 2004), other social insects use cuticular hydrocarbons as nestmate recognition cues that also have the quite significant function of waterproofing the cuticle and preventing desiccation of the insect (Buckley et al., 2003). These cuticular hydrocarbons are also complex mixtures, with alkanes, alkenes, and methylbranched alkanes as the typical components. Usually the alkenes or methyl-branched alkanes serve as cues, while the n-alkanes do not. Based upon this information, we would predict that substitution of cuticular hydrocarbon compounds would not affect the waterproofing function of the complex blend, but this has not been tested, to our knowledge.

In a broader sense, use of external phenotypic characters as signals that vary between genders, among social groups, or among individuals, relies on a mechanism in which changes in signal phenotype do not affect the phenotype for mechanical function. This argument applies whether the cues are chemical, as is the case in nestmate recognition, or visual, as in human facial recognition. Although each human face is unique, for the most part, we all have two eyes, a nose and a mouth that retain their visual, chemosensory and other functions despite substantial variations in their structure. Our results demonstrate how such phenotypic diversity can be tolerated within the constraints of the mechanical demands on a construction material.

This finding supports the hypothesis that increased proportions of hydrogen bonding strengthen wax, but raises the question of whether variation in fatty acid composition, which is essential for the cue function, would result in changes in the mechanical properties of beeswax.

\section{ACKNOWLEDGEMENTS}

We gratefully acknowledge the assistance of John Coyle for his help with mechanical testing instrumentation. Robert Buchwald was supported by an NIH research traineeship - biological sciences, NIH-T32MH016880, PI: Jeanne Wehner.

\section{Le rôle des acides gras dans les propriétés méca- niques de la cire d'abeille.}

Apis mellifera / cire / acide gras / résistance à l'élasticité / rigidité / composition chimique

Zusammenfassung - Die Bedeutung von Fettsäuren für die mechanischen Eigenschaften von Bienenwachs. Bienenwachs stellt eine Mischung vieler organischer Verbindungen dar, darunter Kohlenwasserstoffe, Wachsester und Fettsäuren. Obwohl die Zusammensetzung von Bienenwachs bekannt ist, wissen wir wenig über die Funktion der einzelnen Komponenten. Da die Fettsäuren des Bienenwachses auch an der sozialen Kommunikation beteiligt sind, untersuchten wir die Bedeutung dieser Substanzgruppe für die mechanischen Eigenschaften des Bienenwachses und verwendeten dazu Standardmethoden aus der Materialprüfung.

Konkret überprüften wir dabei, welche Rolle diejenigen Fettsäuren, die für die Erkennung der stockeigenen Bienen verwendet werden, für die mechanischen Eigenschaften des Bienenwachses spielen. Wir verglichen dabei unabhängig von der Architektur oder Geometrie des Wachses drei unterschiedliche Bienenwachsproben: Wachs, von dem die Fettsäuren entfernt wurden, Wachs mit zusätzlich zugesetzten Fettsäuren sowie unbehandeltes Bienenwachs. Danach produzierten wir künstliche Wachsmischungen aus Komponenten des ursprünglichen Bienenwachses und veränderten dabei entweder die relativen Anteile oder die Zusammensetzung der Fettsäuren. Schließlich analysierten wir die Zusammensetzung der Fettsäure-Fraktion im natürlichen Bienenwachs mit GC-MS-Methoden.

Die Entfernung der Fettsäuren aus dem Bienenwachs führte zu einer geringeren Streckspannung, Elastizität, Stabilität und Steifigkeit sowie 
zu einer Abnahme der Proportionalitätsgrenze in der Spannungs-Dehnungs-Kurve. Die Zugabe von Stearinsäure zum Bienenwachs verbesserte all diese Parameter mit Ausnahme der Elastizität. Künstliche Wachsmischungen zeigten eine positive Korrelation zwischen der Menge an Stearinsäure in der Wachsmischung und deren Streckspannung. Weitere Versuche mit künstlichen Wachsmischungen zeigten, dass sich die ungesättigten Fettsäuren im Bienenwachs bzgl. der mechanischen Eigenschaften ähnlich verhalten.

Die chemischen Analysen der kutikulären Kohlenwasserstoffe auf der Oberfläche von Bienenarbeiterinnen ergaben signifikante Unterschiede zwischen Bienenvölkern für die folgenden 4 Fettsäuren: Hexadecansäure, z, z-9, 12 Octadecadiensäure, z, z, z$9,12,15$ Octadecatriensäure und Tetracosansäure. Unsere Ergebnisse unterstützen die Hypothese, dass Fettsäuren wichtig sind für die mechanischen Eigenschaften des Bienenwachses. Wir wissen zwar nicht, welche mechanischen Eigenschaften des Wachses für den Wabenbau der Bienen am wichtigsten sind. Doch sollte Bienenwachs zum einen eine ausreichende Dehnbarkeit und Elastizität haben, um in eine Wabenform gebracht zu werden, trotzdem aber die Festigkeit aufweisen, um als Honigwabe große Gewichte auszuhalten. Vermutlich hat die natürliche Selektion mindestens eine, wenn nicht mehrere dieser Eigenschaften beeinflusst. Da nicht modifiziertes Bienenwachs elastischer ist als Wachs, aus dem die Fettsäuren entfernt wurden, wurde durch Selektion möglicherweise der Fettsäuregehalt des Bienenwachses in Hinblick auf dessen Elastizität optimiert.

\section{Apis mellifera / Bienenwachs / Fettsäure / Streck- spannung / Steifigkeit}

\section{REFERENCES}

Aichholz R., Lorbeer E. (1999) Investigation of combwax of honeybees with high-temperature gas chromatography and high-temperature gas chromatography-chemical ionization mass spectrometry I. High-temperature gas chromatography, J. Chromatogr. A 855, 601-615.

Aichholz R., Lorbeer E. (2000) Investigation of combwax of honeybees with hightemperature gas chromatography and hightemperature gas chromatography-chemical ionization mass spectrometry II: High-temperature gas chromatography-chemical ionization mass spectrometry, J. Chromatogr. A 883, 75-88.

Blomquist G.J., Chu A.J., Remaley S. (1980) Biosynthesis of wax in the honeybee, Apis mellifera L., Insect Biochem. 10, 313-321.

Breed M.D. (1998) Recognition pheromones of the honey bee, Bioscience 48, 463-470.
Breed M.D., Stiller T.M. (1992) Honeybee, Apis mellifera, nestmate discrimination - hydrocarbon effects and the evolutionary implications of comb choice, Anim. Behav. 43, 875-883.

Breed M.D., Garry M.F., Pearce A.N., Hibbard B.E., Bjostad L.B., Page R.E. (1995) The role of wax comb in honey-bee nestmate recognition, Anim. Behav. 50, 489-496.

Breed M.D., Leger E.A., Pearce A.N., Wang Y.J. (1998) Comb wax effects on the ontogeny of honey bee nestmate recognition, Anim. Behav. 55, 13-20.

Breed M.D., Diaz P.H., Lucero K.D. (2004a) Olfactory information processing in honeybee, Apis mellifera, nestmate recognition, Anim. Behav. 68, 921928.

Breed M.D., Perry S., Bjostad L.B. (2004b) Testing the blank slate hypothesis: why honey bee colonies accept young bees, Insectes Soc. 51, 12-16.

Brockmann A., Groh C., Fröhlich B. (2003) Wax perception in honeybees: contact is not necessary, Naturwissenschaften 90, 424-427.

Buchwald R., Breed M.D., Greenberg A.R., Otis G. (2006) Interspecific variation in beeswax as a biological construction material, J. Exp. Biol. 209, 3984-3989.

Buckley S.H., Tregenza T., Butlin R.K. (2003) Transitions in cuticular composition across a hybrid zone: historical accident or environmental adaptation? Biol. J. Linn. Soc. 78, 193-201.

Cassier P., Lensky Y. (1995) Ultrastructure of the wax gland complex and secretion of beeswax in the worker honey-bee Apis mellifera L., Apidologie 26, 17-26.

Chaline N., Sandoz J.C., Martin S.J., Ratnieks F.L.W., Jones, G.R. (2005) Learning and discrimination of individual cuticular hydrocarbons by honeybees (Apis mellifera), Chem. Senses 30, 327-335.

D’Ettorre P., Wenseleers T., Dawson J., Hutchinson S., Boswell T., Ratnieks F.L.W. (2006) Wax combs mediae nestmate recognition by guard honeybees, Anim. Behav. 71, 773-779.

Fröhlich B., Tautz J., Riederer M. (2000a) Chemometric classification of comb and cuticular waxes of the honeybee Apis mellifera carnica, J. Chem. Ecol. 26, 123-137.

Fröhlich B., Riederer M., Tautz J. (2000b) Comb-wax discrimination by honeybees tested with the proboscis extension reflex, J. Exp. Biol. 203, 15811587.

Fröhlich B., Riederer M., Tautz J. (2001) Honeybees discriminate cuticular waxes based on esters and polar components, Apidologie 32, 265-274.

Hepburn H.R., Kurstjens S.P. (1988) The combs of honeybees as composite materials, Apidologie 19, 25-36.

Hepburn H.R., Armstrong E., Kurstjens S. (1983) The ductility of native beeswax is optimally related to honeybee colony temperature, S. Afr. J. Sci. 79, 416-417. 
Hepburn H.R., Bernard R.T.F., Davidson B.C., Muller W.J., Lloyd P., Kurstjens S.P., Vincent S.L. (1991) Synthesis and secretion of beeswax in honeybees, Apidologie 22, 21-36.

Kaatz F.H. (2006) Measuring the order in ordered porous arrays: can bees outperform humans? Naturwissenschaften 93, 374-378.

Kurstjens S.P., Hepburn H.R., Schoening F.R.L., Davidson B.C. (1985) The conversion of wax scales into comb wax by African honeybees, J. Comp. Physiol. B 156, 95-102.

Morgan J., Townley S., Kemble G., Smith R. (2002) Measurement of physical and mechanical properties of beeswax, Mat. Sci. Tech. 18, 463-467.

Pirk C.W.W., Hepburn H.R., Radloff S.E., Tautz J. (2004) Honeybee combs: construction through a liquid equilibrium process? Naturwissenschaften 9, 350-353.
Ratnieks F.L.W. (1991) The evolution of genetic odorcue diversity in social hymenoptera, Am. Nat. 137, 202-226.

Reeve H.K. (1989) The evolution of conspecific acceptance thresholds, Am. Nat. 133, 407-435.

Tibbetts E.A. (2004) Complex social behaviour can select for variability in visual features: a case study in Polistes wasps, Proc. R. Soc. Lond., Ser. B 271, 1955-1960.

Tulloch A.P. (1980) Beeswax - composition and analysis, Bee World 61, 47-62.

Warth A.H. (1956) The Chemistry and Technology of Waxes, 2nd ed., Reinhold Press, New York.

Weaire D., Phelan R. (1994) Optimal design of honeycombs, Nature 367, 123. 